\title{
California's End of Life Option Act: Opportunities and Challenges Ahead
}

\author{
Laura A. Petrillo, $M D^{1,2}$, Elizabeth Dzeng, $M D, P h D, M P H^{3}$, and Alexander K. Smith, MD, MS, MPH ${ }^{1,2}$ \\ 'Division of Geriatrics, Department of Medicine, University of California, San Francisco, San Francisco, CA, USA; ${ }^{2}$ San Francisco Veterans Affairs \\ Medical Center, San Francisco, CA, USA; ${ }^{3}$ Division of Hospital Medicine, Department of Medicine, University of California, San Francisco, San \\ Francisco, CA, USA
}

KEY WORDS: end of life care; palliative care; physician-assisted death; aging; health policy.

J Gen Intern Med 31(8):828-9

DOI: $10.1007 / \mathrm{s} 11606-016-3713-3$

(c) Society of General Internal Medicine 2016

$\mathrm{W}$ hen the End of Life Option Act goes into effect in June of 2016, Californians will be able, for the first time, to ask their physicians for medication to end their lives. Many states introduced similar bills after Brittany Maynard's highly publicized campaign for physician-assisted death in late 2014, but California's End of Life Option Act is the first to pass and may signal a national shift. As the largest and most diverse state in the country, California's response to the law will likely set a precedent that affects many Americans, not just the very few in California who will ultimately use the law to end their lives. Though the path to legalization of physician-assisted death in California was fraught with controversy, at this moment in time, healthcare providers must unite to achieve the best possible care of patients, regardless of whether or not they personally support the practice. Herein we describe the practical clinical, ethical, and policy issues that California, as an example for the country, must address in the wake of the law's passage.

A historical perspective of the first state to legalize physician-assisted death holds valuable lessons for California. When voters passed the Death with Dignity Act in Oregon in 1994, Oregonian healthcare providerssaw the event as a wakeup call that palliative care in Oregon fell short of dying patients' expectations, and were invigorated to work toward change to address the shortcomings. ${ }^{1}$ In the ensuing years, hospice referrals increased $20 \%$. Hospitals created or expanded palliative care consult teams. The Oregon Health and Sciences University bolstered training in palliative care throughout the state. ${ }^{1}$ In a survey conducted two years after the Death with Dignity Act took effect, physicians reported very few requests under the law, and $46 \%$ of patients who made a request changed their minds after physician interven-

Received January 25, 2016

Revised March 22, 2016

Accepted April 8, 2016

Published online April 25, 2016 tions. ${ }^{2}$ Oregon continues to rank among the top states in the country in the provision of excellent palliative care, ${ }^{3}$ and utilization of the Death with Dignity Act remains low.

It may be too soon to tell, but the legalization of physician-assisted death in California has not yet created a sense of urgency to improve care for the dying, as happened in Oregon in 1994. There is certainly room to improve in California; in a 2015 state-by-state report card on access to palliative care, California received a "B" rating (61-80\% of hospitals have access to palliative care services) ${ }^{3}$. Palliative care uptake is particularly low in forprofit hospitals, small hospitals, and community hospitals that are the lone providers for their region ${ }^{3}$. Most requests for physician-assisted death, however, occur in the outpatient setting. On par with the rest of the country, outpatient palliative care in California is even more limited than inpatient services. Outpatient and home-based palliative care programs in California have the capacity to serve only $24-37 \%$ of patients in need, and 22 of 58 counties have no such services. ${ }^{4}$ Nationally, the majority of primary care providers receive no training in palliative care, nor do specialists like oncologists, cardiologists, or nephrologists, who routinely care for seriously ill patients.

Why is access to palliative care important? Many more people support the general concept of physician-assisted death than seriously consider it for themselves; $68 \%$ of people in the USA supported physician-assisted death in a 2015 Gallup poll, but the Death with Dignity Act accounts for only $0.3 \%$ of deaths in Oregon. There are many reasons that the actual rate of the law's usage is low, but one critical factor is that aggressive symptom management, restoring patient control in decision-making, and the provision of hospice care help many people to have a dignified, comfortable death without the need for death-hastening medication. No matter where healthcare providers stand on physician-assisted death philosophically, all agree that maximizing multidisciplinary palliative interventions to address potentially reversible physical, psychological, and spiritual suffering should be standard of care for seriously ill people, and that physician-assisted death should be a last resort, if it is included in the spectrum of options at all. The "Fast Facts" guides to evaluating and responding to patient requests for hastened death are an excellent starting point for all clinicians (available at www.mypcnow.org). When 
specialty palliative care is needed, a national provider directory can be found on the Center to Advance Palliative Care's website www.getpalliativecare.org.

Another important area of focus in California is whether legalization of physician-assisted death will negatively affect vulnerable groups, including racial and ethnic minorities and persons with disabilities. Data from Oregon and Washington have been held up as evidence disproving this concern. However, the finding that predominantly affluent, educated white patients use the law in those states is not sufficient evidence that those at a social disadvantage will be unaffected. California's tremendous diversity will represent a truer test of potential disproportionate use in disadvantaged groups. This could result either from pressure from family, providers, or society to take advantage of the law, or from insufficient access to providers with expertise to explore the meaning behind requests and to respond with interventions that might obviate the request, like pain control and hospice care.

Even if vulnerable patients do not disproportionately use physician-assisted death, existing distrust in the healthcare system may be exacerbated by its legalization. AfricanAmerican patients are less likely than white patients to enroll in hospice at the end of life and more likely to opt for aggressive care. These choices stem, at least in part, from a legacy of unequal treatment that eroded the credibility of the healthcare system. ${ }^{5}$ The addition of physician-assisted death may substantiate suspicion of death-hastening or the devaluing of some lives relative to others, potentially worsening existing disparities in palliative and hospice care. Providers should maintain curiosity and openness in talking about end of life decisions with patients to identify possible barriers to accessing supportive care, and should enlist the aid of spiritual and social support services when appropriate. In addition, only patients, never healthcare providers, should initiate conversations about the End of Life Option Act, since even the presentation of the law as one option among many could imply some degree of approval or encouragement.

In order for the experience of dying patients to improve after the passage of the End of Life Option Act, California needs action on multiple levels. Individual physicians will need training in evaluating patient requests for medication, whether they plan to prescribe or not, including assessment of capacity, symptoms, and reasons for the request, as well as training in basic palliative care to respond to patients' needs. Individual healthcare clinics and facilities must create policies that both support providers who conscientiously object and provide continuity of care to patients who request physician- assisted death. These local policies may add further safeguards, such as requiring provider credentialing to prescribe medications under the law, or mandating a referral to a provider trained in palliative care. On the state health policy level, important steps are being taken to increase palliative care access for low-income patients with Medicaid in California, but these are not enough. California also needs to address the specialist palliative care workforce shortage and increase palliative care training for primary care providers. Researchers should monitor the impact of legalization on vulnerable populations. Engagement of patient advocacy groups from diverse communities will be a key factor in making quality end-of-life care broadly acceptable and accessible.

This is a critical moment for California. There is an enormous opportunity for California to lead the way for other states that might soon legalize physician-assisted death. To do this, California must heed the lessons of Oregon but also address the needs of its own large, diverse population. If these efforts are successful, the End of Life Option Act may be used by only a small number of people - but many more seriously ill patients would stand to benefit.

Acknowledgments: We would like to thank Drs. Eric Widera and Barbara Koenig for their review and comments on this manuscript.

Corresponding Author: Laura A. Petrillo, MD; Division of Geriatrics, UCSF, 4150 Clement St. (181G), San Francisco, CA 94141, USA (e-mail: laura.petrillo@ucsf.edu).

\section{Compliance with Ethical Standards:}

Funding: Dr. Smith was supported by a career development award from the NIA Paul Beeson Career Development Award in Aging (1K23AG040772). Dr. Dzeng was supported by the UCSF Pepper Center.

Conflict of Interest: The authors declare that they do not have a conflict of interest.

\section{REFERENCES}

1. Lee MA, Tolle Sw. Oregon's assisted suicide vote: the silver lining. Ann Intern Med. 1996;124(2):267-9.

2. Ganzini L, Nelson HD, Schmidt TA, Kraemer DF, Delorit MA, Lee MA. Physicians' experiences with the Oregon death with dignity act. N Engl J Med. 2000;342(8):557-63.

3. Dumanovsky T, Augustin R, Rogers M, Lettang $\mathbf{K}$, Meier DE, Morrison RS. The growth of palliative care in U.S. hospitals: a status report. J Palliat Med. 2016;19(1):8-15.

4. Gueale K, Meyers, $\mathbf{K}$. Dying in California: a status report on end-of-life care [Internet]. 2015 [cited 2016 April 5]; Available from: http://www.chcf.org/ publications/2015/10/dying-calif-status-report.

5. Crawley L, Payne R, Bolden J, et al. Palliative and end-of-life care in the African American community. JAMA. 2000;284(19):2518-21. 